\title{
Current Challenges and Future in Engineering Education
}

\author{
Dr. P. N. Razdan \\ Vice Chancellor, Dr. D. Y. Patil University, Pune
}

Introduction : India has one of the youngest populations in the world and a very large pool of young English-speaking people. As per UN World Population Prospects Database 2004, one in five in the world will be Indian with $65 \%$ of population below the age of 35 years. Furthermore, as per recent survey, India will become World's 3rd Biggest economy by 2050. Thus we need to create capabilities to meet the skills needs of other countries and also cater to its own demand for trained manpower. Government has already launched "Make in India" campaign with an aim to turn the country into a global manufacturing hub.

India is presently experiencing a skills shortage in the engineering profession. There is a general consensus among engineering educators, entrepreneurs, industry and business leaders that engineering education in India is in crisis. Employability of Indian Engineering Graduates is a great Challenge before the nation. Globalization has brought in a clear shift from education as transmission of expert knowledge to education as building learner competencies including learning to learn and lifelong learning. The focus must be on understanding fundamentals very well and

\section{Dr. P. N. Razdan}

Vice Chancellor,

Dr. D. Y. Patil University, Pune learning new skills/competencies that would enable individuals to cope with the demands of the rapidly changing workplace. Prepare global engineers who will have to solve problems and shoulder challenges which are not even known today. Engineering mathematics and the sciences are the prime areas which can bring the products, services, standard of living, and economic and military security that will sustain us at home and around the world. The technological creativity will come from those areas.

We are confronted with a huge demand on welleducated and highly-qualified engineers and scientists that will keep growing in the future. Therefore, we are facing grand challenges with respect to this demand. Recommendations and Action Points for engineering education in India to be undertaken over the next few decades in the areas of:

- Improving the Quality of Teaching, Learning and Research at Engineering Institutions. Energizing all the faculty to understand the goals and approaches and ensure their full involvement

- Establish compulsory training in teaching pedagogy.

Fostering Stronger Industry/Institute Collaboration

- Building Innovation and Entrepreneurship in Engineering Education

Increase the number of autonomous engineering 
institutions so as to facilitate quick revision of the Curriculum

Up to 25 percent of faculty in engineering institutions should be qualified personnel from industry and research organizations

- Strengthening Governance, Leadership and Management at Engineering Institutions

Make internship a routine mandatory practice for all engineering students over ten years;

Create University /Industry Consortia for applied research, and engineering based on marked demands;

- Establishing Incubation-centers/warehouses, fabrication centers at Institutes based on marked demands.

- Technical subjects require that students be exposed to examples of the use of engineering principles as applicable in real life.

There is no doubt that quantitative growth of engineering education in India has increased the opportunities for engineering aspirants and has contributed to nation's growth. But the maintenance of quality has become the victim of this growth phenomenon. Lack of maintenance of standards in institutions and failure to monitor the same by the regulating bodies is the main factor responsible for this scenario in the country.

National Board of Accreditation (NBA) is entrusted with the task of periodically evaluating technical institutions and programs based on the norms and standards laid down by the All India Council of Technical Education (AICTE). The motive of accreditation is to encourage excellence in technical institutions at the UG and PG levels. NBA changed its accreditation norms and procedure in 2009 to be in tune with international standards as per the Washington Accord which is an International Partnership of like-minded Accreditation Agencies of 18 countries. Washington Accord, Recognizes the "substantial equivalency" of an accreditation system within a country - that assesses/assures that the graduates of accredited program in their country are prepared to practice engineering at the entry level of the profession. In India it will help create equivalence of engineering degree courses and allow Indians to practice engineering in other member countries. This will assure that graduates are adequately prepared to enter the practice of engineering and have new and innovative approaches to engineering education and its assessment. Furthermore, it will bring Confidence and assurance on quality to various stakeholders including students.Enabling an Institution to state publicly that it has voluntarily accepted independent inspection and has satisfied all the requirements for satisfactory operation and maintenance of quality in education.

NBA while assessing the technical programmes will ensure that following Graduate Attributes are acquired by the students during their stay in the institutes

- Engineering knowledge so that students are able to apply the knowledge of mathematics, science, engineering fundamental to the solution of complex engineering problems

- Problem Analysis, so that students are capable to Identify, formulates and analyzes engineering problems to arrive at substantiated conclusions using first principles of mathematics, natural, and engineering sciences.

- Design solutions for complex engineering problems and design system components, processes to meet the specifications with consideration for the public health and safety, and the cultural, societal, and environmental considerations.

- Investigations of complex problems: by using their knowledge including design of experiments, analysis and interpretation of data, and synthesis of the information to provide valid conclusions.

Technical institutes must ensure that students are having desirable qualities that can be emphasized to meets a program's mission such as :

- Technical: the specialized skills that are required by a practitioner in the discipline.

- Business: the skills required to function within a larger enterprise.

- Communication: the skills to convey information effectively using a variety of methods, and media.

Professionalism: the personal and professional conduct and qualities expected for a practicing engineer. 
Individual - Skills such as creativity, leadership, innovation, and practical ingenuity

The impel task is to formulation of Programme Objectives with the participation of all stakeholders. Furthermore, assessing Programme outcome by equipping students with knowledge, skills and attitudes relating to specified outcome and to develop instructional techniques and assessment procedures to prepare students to achieve those outcomes.

Recent studies have show, that the study time students spent in college is declining and targeting solutions will necessarily require close cooperation between science and research, industry and governments at regional, national level. Better mentoring and supervision of students especially in their initial phase is highly desirable as many students have difficulties to cope with the different requirements at universities in comparison to high school.

The Indian as well as the global knowledge society must tackle these grand challenges through candid analyses, powerful actions and increased resources. Universities of technology will have to play key roles in these developments as they educate and train the tomorrow's engineers for the knowledge society. Teachers at university are the important leaders in our society who can contribute to provide solutions in following ways:

Attract more young people to science and technology.

- Convey our passion and enthusiasm for science and technology to the youth.

Attract and to develop good teachers for preschool education, school and high schools as

well as for universities.

- Improve the quality of mathematics and science education.

- Decrease the drop-out rate of students without decreasing standards in education.

In order to produce more competent and qualified engineers and scientists who are globally competent we need to initiate two prong strategy: (i) by getting the youth more interested in STEM (Science,
Technology, Engineering, and Mathematics) and (ii) by fostering them to keep them on a science or engineering track instead of losing them during their academic education. The first needs societal efforts and should start already during pre-school education. The second can be achieved by many different measures:

Furthermore, most study programs focus especially on a strong theoretical fundament during the first semesters. Bringing their study in close contact with technology will elevate their motivation by giving them the feeling of the huge practical value of theory.

To keep the level of qualification of future engineers, students have to be forced to better train their mathematical skills. Scientist and engineers need high-level mathematical "literacy". Like reading, doing the basics in mathematics has to be automated. This releases brain capacity which is needed for the creative process of understanding and problemsolving. As a consequence, reasoning has to be in the focus and the usage of computers in the exercise lessons has to be limited to a reasonable degree.

Vocational subject need to be made compulsory at the plus 2 level for all students. It may be argued that there are separate schools for vocational education. Unfortunately, many consider such schools/courses as "inferior" and it affects their dignity. It would also foster dignity of labor, something woefully absent in our culture. Education in India needs to more skill oriented - both in terms of life-skills as well as livelihood skills. In sheer numerical terms, India has the man power to substantially meet the needs of a world hungry for skilled workers, provided its education system can convert those numbers into a skilled work-force with the needed diversity of skills

India has some very bright spots of excellence in its technical education sector. Hence India will play a significant role in human resource development and capacity building of individuals, to cater to the needs of the economy, society, the country and the world at large. India expects the educational institutions to perform as good as their global partners which need significant technological innovations. The IITs and their alumni command great respect in the global market. India's second-tier engineering schools are also well-regarded, and have excellent faculty and student bodies. AICTE needs to focus on ensuring that its standards are met at already existing institutions, 
and that faculty shortages are reversed by investing in postgraduate education and encouraging talented students to remain in India to pursue careers in academia There is need to address the problems ailing the technical education otherwise India will miss the opportunity to utilize its demographic dividend of a young work force which it has. In order to ensure standards as per global norms and mechanism to monitor the same, uncompromising attitude is essential. Accreditation framework in place helps the engineering education to encourage excellence and maintain quality in education. 